\section{Bovine TB: don't get rid of the cat because the mice have gone}

\section{SIR - Paul Torgerson and David Torgerson argue in Correspondence that research and surveillance for tuberculosis (TB) in cattle can only be justified on animal-health grounds because bovine TB poses a negligible threat to human health ('Does risk to humans justify high cost of fighting bovine TB?' Nature 455, 1029; 2008). But the relationship between surveillance of cattle and the risk of humans contracting the disease is not as simple as they imply. \\ The current surveillance to Agency, Weybridge, Addlestone, Surrey KT15 3NB, UK, and Centre for the Study of Evolution, John Maynard Smith Building,University of Sussex, Brighton BN1 9QG, UK e-mail: n.h.smith@vla.defra.gsi.gov.uk Richard Clifton-Hadley Veterinary Laboratories Agency, Weybridge, Addlestone, Surrey, KT15 3NB, UK \\ Bovine TB: stopping disease control would block all live exports} remove infected cattle at an early stage in the disease process reduces the prevalence and, more important, curtails the course of the disease in individual cattle. This is particularly relevant in areas of higher incidence, where testing is an annual event. For example, three UK counties breached 10\% herd incidence of confirmed cases in 2007.

Without a test-and-cull policy and abattoir surveillance, bovine TB would advance to its more infectious stages and lead to an increased risk of transmission of this primarily airborne disease to humans. Removing animals at an early stage and controlling the prevalence of the disease in the national herd is therefore likely to reduce the probability of transmission to humans.

We would argue that active surveillance for bovine TB followed by the removal of infected cattle is part of the reason why this disease is not seen more often in humans. When using a cat to control mice, you shouldn't get rid of the cat just because you don't see any more mice.

We agree that protecting animal health and reducing losses in animal productivity are important justifications for surveillance and research of bovine TB. But keeping the risk of human exposure as low as possible must also be factored into the equation.

Noel H. Smith Veterinary Laboratories

SIR - In their Correspondence, Paul Torgerson and David

Torgerson question the importance of controlling bovine tuberculosis (TB) in the United Kingdom ('Does risk to humans justify high cost of fighting bovine TB?' Nature 455, 1029; 2008).

However, they disregard the crucial role of disease control in protecting international trade a key reason why the UK government is trying to eradicate bovine TB.

To be exported from the United Kingdom, cattle aged 42 days or older must have tested negative for bovine TB within the previous 30 days. In 1995, the value of live cattle exports was $€ 77.6$ million (US\$115 million); after the imposition of the ban on exports because of BSE (bovine spongiform encephalopathy), this fell to zero (see http://tinyurl. $\mathrm{com} / 6 \mathrm{j} 802 \mathrm{w}$ ). Although the ban on exports from the United Kingdom was lifted in 2006, live cattle exports are only just now starting to recover.

To stop control of bovine TB would once again block all live exports. UK government expenditure on the foot-andmouth disease outbreak in 2001 was $€ 2.79$ billion, and the protection of international trade was a key driver of the control measures used at that time (see http://tinyurl.com/67p9g5).
The protection of trade status is one aspect of an integrated policy for controlling bovine TB that safeguards public health and the agricultural economy as well as animal health and welfare. Indeed, as we face an increasing problem with bovine TB in the United Kingdom, the success of this control strategy in protecting public health is evidenced by the sporadic nature of Mycobacterium bovis infections in the human population (see A. L. Gibson et al. J. Clin Microbiol. 42, 431-434; 2004; J. T. Evans et al. Lancet $369,1270-1276 ; 2007$ ). Now is not the time to dismantle controls for bovine TB.

Stephen V. Gordon UCD College of Life Sciences and UCD Conway Institute of Biomolecular and Biomedical Research, University College Dublin, Belfield, Dublin, Ireland

e-mail:stephen.gordon@ucd.ie

\section{Right environment can enhance 'innate' entrepreneurial skills}

SIR - In their Commentary 'The innovative brain' (Nature 456, 168-169), Barbara Sahakian and her colleagues raise the important question of whether entrepreneurial skills can be taught. In my experience, an entrepreneur's 'cold' skills (in creating a compelling business plan, for example) are easier to teach than the more intuitive 'hot' decision-making abilities that stimulate success.

Successful entrepreneurs have enormous energy, think independently and show inspiring leadership qualities that help to realize a shared vision. However, their flair for weighing up and pursuing the best opportunities is honed by past experience for example, in spotting promising factors in new companies. An entrepreneur's natural ability is founded in the interaction of genes and environment.

During the past 20 years I have participated in the development of the entrepreneurial environment here in Cambridge. In 1997, only $17 \%$ of the entrepreneurs in our portfolio companies were 'serial entrepreneurs' people who already had a record of achievement. Now this percentage has risen to $70 \%$, which reflects the rapid increase in entrepreneurial talent in Britain. Today there are more than 1,000 high-tech companies in Cambridge alone, with at least one entrepreneur involved in each of them.

Know-how is transmitted 'in the air' within these high-technology clusters. They are also valuable in tolerating risk and possible failure well: as bioscience entrepreneur Andy Richards has pointed out, Cambridge has become a low-risk area for doing high-risk things. This entrepreneurial environment promotes venturesome behaviour in the face of risky business opportunity. Failure carries no stigma when it is recognized as a necessary part of the entrepreneurial process as it is here - given that some $30 \%$ of all new companies will fail anyway.

Entrepreneurial activities and innovative ideas are particularly needed in today's economic climate, both for the wealth of the United Kingdom and for the global economy. Understanding how the innate components of these abilities can be enhanced will help to educate the next generation of entrepreneurs for success.

Hermann Hauser, Amadeus Capital, Mount Pleasant House, 2 Mount Pleasant, Cambridge CB3 ORN, UK e-mail: hhauser@amadeuscapital.com

Readers are welcome to comment at http://tinyurl.com/5opr6g

Contributions may be submitted tocorrespondence@nature.com. Correspondence should be signed by no more than three authors; preferably by one. Published contributions are edited. Science publishing issues are regularly featured at Nautilus (http://blogs. nature.com/nautilus), where we welcome comments and debate. 